\title{
Changement climatique : tous concernés !
}

\section{Christelle Audouit}

\section{(2) OpenEdition \\ Journals}

Édition électronique

URL : http://journals.openedition.org/developpementdurable/10876

DOI : 10.4000/developpementdurable.10876

ISSN : 1772-9971

Éditeur

Association DD\&T

\section{Référence électronique}

Christelle Audouit, «Changement climatique : tous concernés! », Développement durable et territoires [En ligne], Vol. 6, n² | Septembre 2015, mis en ligne le 30 septembre 2015, consulté le 24 septembre 2020. URL : http://journals.openedition.org/developpementdurable/10876 ; DOI : https://doi.org/ 10.4000/developpementdurable.10876

Ce document a été généré automatiquement le 24 septembre 2020.

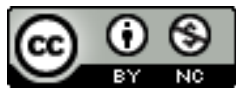

Développement Durable et Territoires est mis à disposition selon les termes de la licence Creative Commons Attribution - Pas d'Utilisation Commerciale 4.0 International. 


\title{
Changement climatique : tous concernés!
}

\author{
Christelle Audouit
}

1 Ce nouveau numéro de la revue Développement Durable et Territoires apparaît à point nommé, à quelques jours de l'ouverture de la COP 21 à Paris (du 30 novembre au 11 décembre 2015), évènement déterminant qui vise à aboutir à un nouvel accord international sur le climat, avec des engagements chiffrés de tous les pays signataires, dans l'objectif de maintenir le réchauffement mondial en deçà de $2^{\circ} \mathrm{C}$ à l'horizon 2100 . L'enjeu est de parvenir à un accord-cadre - un accord global - sur le climat pour devenir effectif à partir de 2020, en s'appuyant sur un mode opératoire pour mesurer et vérifier les émissions de gaz à effet de serre. Il devrait être fondé à partir des politiques nationales et non plus comme pour l'accord de Kyoto, sur un accord international contraignant (ce dernier ayant montré ces limites). Ces contributions nationales seraient de nature hétérogène aux ambitions modestes à moyen terme, déterminées pour tous les États signataires ainsi que la Chine.

2 Comme le disent les auteurs Michel Damian, Medhi Abbas et Pierre Berthaud ${ }^{1}$ dans le numéro 23 de Natures Sciences Sociétés intitulé « Les enjeux de la conférence de Paris. Penser autrement la question climatique ", les sociétés s'engagent dans la transition énergétique, chacune à leur rythme, sous différentes formes. Et heureusement car l'accord de Paris n'apportera pas toute la solution à la crise climatique ! L'un des grands enjeux de ces débats n'est-il pas d'insuffler un certain dynamisme pour développer notre capacité d'adaptation et avoir une consommation plus en adéquation avec les ressources disponibles (espace, énergie, ...) ?

3 Au vu du programme de la COP 21, les villes seront au cœur du débat. Penser autrement le rapport de la ville à son environnement et à la question du lien social, tels sont les objectifs des éco-quartiers dont les expériences se multiplient. Ceux-ci amènent à s'interroger sur le mode d'habiter qui inclut les notions de genre de vie et des modes de vie. La première sous-entend les modes d'adaptation et d'utilisation d'un milieu, et la deuxième se réfère aux « habitus » des individus, leurs comportements avec les groupes sociaux. Le présent numéro de la revue Développement Durable et Territoires comporte 
un dossier coordonné par Aurélie Carimentrand, Valérie Deldrève, Abdourahmane Ndiaye et Pascal Tozzi sur la participation au sein des écoquartiers.

Concilier bien-être et transition écologique devient pour beaucoup de personnes un idéal à atteindre dans les actes du quotidien (bien qu'il reste encore beaucoup à faire !) : se déplacer en vélo, consommer des produits à circuit court, des produits de saison, recycler, penser et agir pour réduire sa consommation d'énergie dans le cadre de son logement et de sa mobilité... Bien des initiatives citoyennes promeuvent des modes de vie visant à réduire, à l'échelle micro, l'inadéquation entre ressources et consommation. N'est-ce pas de concert entre citoyens et pouvoirs publics qu'il faut réfléchir et agir et ce à toutes les échelles? La difficulté étant actuellement l'articulation entre les initiatives locales et la gouvernance nationale. Les mouvements participatifs sont essentiels et demeurent un des piliers de la réussite des projets pour cette transition énergétique. L'adaptation est plus que jamais à l'ordre du jour. Les moyens dont dispose chaque pays pour s'adapter au changement climatique seront aussi évoqués et intégrés à l'agenda des négociations pour le futur Accord de Paris. Cette notion d'adaptation fait la part belle aux innovations technologiques comme organisationnelles et engage des enjeux de solidarité. À ce propos, je profite de cet éditorial pour vous annoncer la parution prochaine d'un numéro qui comportera le premier volet d'un dossier sur « L'adaptation en tensions ».

\section{NOTES}

1. Damian M., Abbas M. et Berthaud P., 2015, «Les grandes orientations de l'accord climatiques de Paris 2015 », Natures Sciences Sociétés, n²3, supplément, S19-S28 (2015).

\section{AUTEUR}

\section{CHRISTELLE AUDOUIT}

Christelle Audouit est géographe littoraliste et membre du comité de rédaction de Développement Durable et Territoires. Ingénieure de recherche en Production et analyse de données au Laboratoire Territoires, Villes, Environnement et Société (TVES EA 4477) à

l’Université Lille,christelle.audouit@univ-lille1.fr 